\title{
Neurosurgical treatment and outcome patterns of meningioma in Sweden: a nationwide registry-based study
}

\author{
Alba Corell $^{1,2}$ (D) Erik Thurin ${ }^{2,3} \cdot$ Thomas Skoglund $^{1,2} \cdot$ Dan Farahmand $^{1} \cdot$ Roger Henriksson $^{4,5} \cdot$ Bertil Rydenhag $^{1,2}$. \\ Sasha Gulati $^{6,7}$ • Jiri Bartek Jr ${ }^{8,9,10}$ - Asgeir Store Jakola ${ }^{1,2,6}$
}

Received: 20 October 2018 / Accepted: 4 January 2019 / Published online: 24 January 2019

(C) The Author(s) 2019

\begin{abstract}
Background Surgery is the main treatment modality for intracranial meningiomas, but data on short-term surgical outcome are limited. The aim of this Swedish nationwide registry-based study was to benchmark the 30-day complication rate in a cohort of meningioma patients using data from the Swedish brain tumor registry (SBTR). Furthermore, we investigated outcomes for asymptomatic patients.

Methods Data were collected from the SBTR for all adults with histopathologically verified intracranial meningioma between 2009 and 2015. Patient symptoms, tumor characteristics, and complications within 30 days postoperatively were analyzed.

Results In total, 2324 patients, with a mean age of 58.7 years (SD 13.5), underwent surgery for intracranial meningioma and $14.1 \%$ of the patients were asymptomatic before the intervention. The most common symptom prior to treatment was focal deficit, which occurred in 1450 patients (62.4\%). Moreover, within 30 days after surgery, 344 patients (14.8\%) developed new neurological deficits and new-onset seizures occurred in 105 patients (4.5\%), while $8.3 \%$ of asymptomatic patients developed neurological deficit and $3.7 \%$ new-onset seizures. Due to complications, reoperations were performed in 120 patients (5.2\%). The postoperative 30 -day mortality in the whole cohort was $1.5 \%$.

Conclusion This study benchmarks the 30-day complication rate after meningioma surgery and provides outcome data in the highly relevant group of asymptomatic patients using data from the Swedish brain tumor registry. Since surgical decision-making is a careful consideration of short-term risk versus long-term benefit, this information may be useful for both caregivers and patients.
\end{abstract}

This article is part of the Topical Collection on Tumor - Meningioma

\author{
Alba Corell \\ alba.corell@vgregion.se \\ Erik Thurin \\ erik.thurin@gmail.com \\ Thomas Skoglund \\ thomas.skoglund@vgregion.se \\ Dan Farahmand \\ dan.farahmand@gmail.com \\ Roger Henriksson \\ roger.henriksson@umu.se \\ Bertil Rydenhag \\ bertil.rydenhag@vgregion.se \\ Sasha Gulati \\ sashagulati@ntnu.no \\ Jiri Bartek, Jr \\ jiri_bartek@hotmail.com \\ Asgeir Store Jakola \\ asgeir.jakola@vgregion.se
}

1 Department of Neurosurgery, Sahlgrenska University Hospital, Gothenburg, Sweden

2 Institute of Neuroscience and Physiology, Sahlgrenska Academy, University of Gothenburg, Gothenburg, Sweden

3 Department of Neurology, Sahlgrenska University Hospital, Blå stråket 5, 41345 Gothenburg, Sweden

4 Regional Cancer Centre Stockholm, Stockholm, Gotland, Sweden

5 Department of Radiation Science and Oncology, University hospital, Umeå, Sweden

6 Department of Neurosurgery, St. Olavs University Hospital, Trondheim, Norway

7 Department of Neuromedicine and Movement Science, Norwegian University of Science and Technology, Trondheim, Norway

8 Department of Neurosurgery, Karolinska University Hospital, Stockholm, Sweden

9 Department of Clinical Neuroscience and Department of Medicine, Karolinska Institutet, Stockholm, Sweden

10 Department of Neurosurgery, Copenhagen University Hospital Rigshospitalet, Copenhagen, Denmark 
Keywords Neurosurgery $\cdot$ Meningioma $\cdot$ Health registry $\cdot$ Population-based

\section{Introduction}

Meningiomas are the most common intracranial extraaxial tumor and most of them are benign (i.e., World Health Organization (WHO) grade I) [6, 24, 30]. Common symptoms include seizures, headache, personality change, confusion, and focal deficit depending on anatomical location [33]. However, meningiomas may also be an incidental finding in asymptomatic patients [42]. Increased availability of MRI has led to more incidental findings of benign intracranial tumors [1,37], and referral of asymptomatic patients with small incidental meningiomas is frequently encountered in clinical practice. Meningiomas usually have a slow growth rate, and literature suggests that meningiomas in elderly patients grow slower than in younger patients [28], although some longterm data of incidental meningiomas show that the majority of meningiomas eventually grow [18].

For patients with meningioma, surgery is the main treatment modality and offers the possibility of cure [7]. Nevertheless, surgery may cause significant complications [5, 14]. Information about anticipated clinical course, including the short-term risks, is needed for patient information and informed consent. This is a common dilemma in surgery, weighing the risk of shortterm complications and neurological impairment against natural history of disease and the expected long-term results. This equation may be especially challenging for asymptomatic patients with presumed WHO grade I meningiomas where the intention of treatment is to delay or prevent later symptoms and possibly provide better chances of a cure, but with no short-term benefit.

It is well known that following brain tumor surgery, transient neurological deficits may occur [11]. Due to the long-term treatment aim in patients with meningiomas (i.e., cure), there are several studies reporting on long-term outcome of patients, but less information is available concerning short-term morbidity [2, 22, 44]. Information on short-term outcome, supplemented by information on expected long-term outcome available in literature, may educate patients and thus facilitate coping in the immediate postoperative period, since the clinical experience indicates that short-term morbidity is far from trivial.

The aim of this registry-based study was to benchmark the complication rate within 30 days in a Swedish nationwide cohort of meningioma patients using data from the Swedish brain tumor registry (SBTR). Further, we investigated outcomes in the highly relevant group of asymptomatic patients.

\section{Materials and methods}

\section{The Swedish brain tumor registry}

The SBTR is a regionally based nation-wide registry of adult patients (18 years or older) with histopathologically verified brain tumors that was initiated in 1999 [4]. In the Swedish health care system, six different regions provide neurosurgical care to patients with tumors in the central nervous system (CNS). All regions report to SBTR; however, the level of coverage has varied between the different regions over time.

\section{Study population}

We aimed to include all patients in SBTR with intracranial meningioma treated surgically in Sweden from 2009 to 2015 to provide actuality of the current neurosurgical practice. However, in our study, we have only used data from regions where the registration was $80 \%$ or more (for any given year) to provide truly representative and population-based data. Registration rate was defined as percentage of diagnoses in the SBTR that corresponds to diagnoses reported to the compulsory National Cancer Registry. For this reason, in one region, we used data from 2012 to 2013 only. In all other regions, the inclusion period for this study was from 2009 through 2015.

\section{Variables}

All regions in Sweden report to the SBTR data concerning baseline characteristics, lead times, and outcomes following treatment. The variables registered in the SBTR following surgery are described in detail in Table 1.

\section{Statistics}

All analyses were done with SPSS, version 24.0 (Chicago, IL, USA). Statistical significance level was set to $p<0.05$ and all tests were two-sided. Central tendencies were presented as means $\pm \mathrm{SD}$, or median and interquartile range if skewed. Categorical data were analyzed with Pearson's Chi-square test, independent sample $t$ test, or Mann-Whitney $U$ test, as appropriate. For survival, we present Kaplan-Meier curves compared with log-rank test. To identify possible predictors of neurological deficits in asymptomatic patients, we performed a post hoc multivariable logistic regression analysis, selecting predictors based upon presumed clinical relevance. 
Table 1 Definitions of variables

\begin{tabular}{|c|c|}
\hline Variable & Definition \\
\hline Age & Years at time of diagnosis \\
\hline Sex & Male or female \\
\hline Symptoms at diagnosis & $\begin{array}{l}\text { - Asymptomatic (yes/no) } \\
\text { - Focal deficit (yes/no) } \\
\text { - Seizure (yes/no) } \\
\text { - ICP related (e.g., headache, cognition) (yes/no) }\end{array}$ \\
\hline WHO performance status & $\begin{array}{l}\text { Grade } 0 \text {, fully active, able to carry on all pre-disease performance without restriction } \\
\text { Grade I, restricted in physically strenuous activity but ambulatory and able to carry } \\
\text { out work of a light or sedentary nature, e.g., light house work, office work } \\
\text { Grade II, ambulatory and capable of all self-care but unable to carry out any work } \\
\text { activities. Up and about more than } 50 \% \text { of waking hours } \\
\text { Grade III, capable of only limited self-care, confined to bed or chair more than } 50 \% \\
\text { of waking hours } \\
\text { Grade IV, completely disabled. Cannot carry on any self-care. Totally confined to } \\
\text { bed or chairGrade V, dead }\end{array}$ \\
\hline Date of imaging diagnosis & dd.mm.yyyy \\
\hline Laterality & Left/right/bilateral \\
\hline Multifocal & Yes/no \\
\hline Largest diameter of tumor & $\begin{array}{l}<4 \mathrm{~cm} \\
4-6 \mathrm{~cm} \\
>6 \mathrm{~cm}\end{array}$ \\
\hline Date of surgery & dd.mm.yyyy \\
\hline Type of surgery & Biopsy or resection \\
\hline Simpson grade & $\begin{array}{l}\text { Grade I, total removal } \\
\text { Grade II, tumor removal and coagulation of attachment } \\
\text { Grade III, tumor removal without coagulation } \\
\text { Grade IV, subtotal removal } \\
\text { Grade V, decompression/biopsy }\end{array}$ \\
\hline Complication within 30 days & Yes/no \\
\hline New or worsened focal deficit within 30 days & Yes/no \\
\hline New onset seizure within 30 days & Yes/no \\
\hline Any infection within 30 days & Yes/no \\
\hline Any VTE within 30 days & Yes/no \\
\hline Any hematoma within 30 days & Yes/no \\
\hline Complication leading to reoperation within 30 days & Yes/no \\
\hline Date of discharge neurosurgical department & dd.mm.yyyy \\
\hline Histopathology & $\begin{array}{l}\text { SNOMED codes } \\
\text { Meningioma: } 95399,95301,95303,95310,95330,95340,95381,95383,95391\end{array}$ \\
\hline
\end{tabular}

\section{Results}

\section{Baseline characteristics}

In total, 2324 patients that underwent surgery for intracranial meningioma were included. The mean age was 58.7 years $(\mathrm{SD} \pm 13.5)$ and 1638 patients were females $(70.5 \%)$. There were 349 patients $(15.0 \%)$ with skull base meningiomas. Patients presented most often with focal deficit $(n=1450$, $62.4 \%$ ) while 327 patients $(14.1 \%)$ were asymptomatic. The median time from imaging to surgery was 10 weeks (IQR 4 24). Baseline characteristics are presented in Table 2.

\section{Clinical outcome}

Gross total resection (GTR), defined as Simpson grades 1-3, was achieved in $86.6 \%$ of the cohort. Focal neurologic deficits occurred in $14.8 \%$ of the patients within 30 days of surgery. Venous thromboembolism (VTE) occurred in $3.0 \%$ of patients while new-onset seizure occurred in $4.5 \%$ of patients. When analyzing patients registered as seizure-free preoperatively, $4.8 \%$ experienced new-onset seizures (173 cases without either preoperative or postoperative status excluded from analysis). Symptomatic postoperative hematoma were registered in $9.4 \%$ of the patients while reoperation within 30 days due to 
Table 2 Baseline characteristics

\begin{tabular}{|c|c|c|c|c|}
\hline & $\begin{array}{l}\text { Total } \\
(N=2324)\end{array}$ & $\begin{array}{l}\text { Asymptomatic } \\
(N=327)\end{array}$ & $\begin{array}{l}\text { Symptomatic } \\
(N=1996)\end{array}$ & $p$ value \\
\hline Age, mean (SD) & $58.7(13.5)$ & $56.1(13.6)$ & $59.1(13.4)$ & $<0.001$ \\
\hline Age groups & & & & $<0.01$ \\
\hline $18-39, n(\%)$ & $207(8.9)$ & $42(12.9)$ & $165(8.3)$ & \\
\hline $40-59, n(\%)$ & $924(39.8)$ & $140(42.9)$ & $784(39.3)$ & \\
\hline $60-79, n(\%)$ & $1084(46.7)$ & $135(41.4)$ & 949 (47.6) & \\
\hline 80 or older, $n(\%)$ & $105(4.5)$ & $9(2.8)$ & $96(4.8)$ & \\
\hline Female, $n(\%)$ & $1637(70.5)$ & $243(74.3)$ & $1394(69.8)$ & 0.10 \\
\hline Preop MRI, $n(\%)$ & $2165(93.2)$ & $292(90.1)$ & $1873(93.8)$ & 0.01 \\
\hline \multicolumn{5}{|l|}{ missing, $n=3$} \\
\hline \multicolumn{4}{|l|}{ Tumor size, $n(\%)$} & $<0.001$ \\
\hline$<4 \mathrm{~cm}$ & $1002(43.1)$ & $193(70.2)$ & $809(49.3)$ & \\
\hline $4-6 \mathrm{~cm}$ & $660(28.4)$ & $58(21.1)$ & $602(36.7)$ & \\
\hline$>6 \mathrm{~cm}$ & $253(10.9)$ & $24(8.7)$ & $229(14.0)$ & \\
\hline \multicolumn{5}{|l|}{ missing, $n=409$} \\
\hline Skull base, $n(\%)$ & $348(15.0)$ & 38 (11.6) & $310(15.5)$ & 0.07 \\
\hline Posterior fossa, $n(\%)$ & $215(5.4)$ & $19(5.8)$ & $196(5.3)$ & 0.71 \\
\hline \multicolumn{4}{|l|}{ Laterality } & 0.02 \\
\hline Right, $n(\%)$ & $830(42.6)$ & $135(49.8)$ & $695(41.5)$ & \\
\hline Left, $n(\%)$ & 969 (49.8) & $123(45.4)$ & $846(50.5)$ & \\
\hline Bilateral, $n(\%)$ & $147(7.6)$ & $13(4.8)$ & $134(8.0)$ & \\
\hline missing, $n=377$ & & & & \\
\hline Multifocal, $n(\%)$ & $183(7.9)$ & $35(10.9)$ & $148(7.4)$ & 0.04 \\
\hline \multicolumn{5}{|l|}{ missing, $n=14$} \\
\hline Asymptomatic, $n(\%)$ & $327(14.1)$ & $327(14.1)$ & - & - \\
\hline \multicolumn{5}{|l|}{ missing, $n=1$} \\
\hline Focal deficit, $n(\%)$ & $1450(62.4)$ & - & $1450(62.4)$ & - \\
\hline \multicolumn{5}{|l|}{ missing, $n=170$} \\
\hline Seizures, $n(\%)$ & $564(24.3)$ & - & $564(24.3)$ & - \\
\hline \multicolumn{5}{|l|}{ missing, $n=170$} \\
\hline ICP related, $n(\%)$ & $863(40.1)$ & - & $863(40.1)$ & - \\
\hline \multicolumn{5}{|l|}{ missing, $n=170$} \\
\hline \multicolumn{4}{|l|}{ Performance status, n (\%) } & $<0.001$ \\
\hline 0 & $1041(47.0)$ & $235(73.2)$ & $806(42.5)$ & \\
\hline 1 & $639(28.8)$ & $58(18.1)$ & $581(30.7)$ & \\
\hline 2 & $348(15.7)$ & $20(6.2)$ & $328(17.3)$ & \\
\hline 3 & $163(7.4)$ & $7(2.2)$ & $156(8.2)$ & \\
\hline 4 & $25(1.1)$ & $1(0.3)$ & $24(1.3)$ & \\
\hline missing, $n=108$ & & & & \\
\hline $\begin{array}{l}\text { Imaging diagnosis to surgery, median, } \\
\text { weeks (IQR) }\end{array}$ & $10(4-24)$ & $29(13-93)$ & $8(3-20)$ & $<0.001$ \\
\hline
\end{tabular}

${ }^{*} p$ value comparison between symptomatic and asymptomatic

any complication was performed in $5.2 \%$ of the patients. We analyzed if survival differed across WHO groups because we had no central review of pathology, and as shown in Fig. 1, the survival curves separated the groups as expected. Further details are presented in Table 3 . The postoperative 30-day mortality was $1.5 \%$ in the whole cohort $(p=0.06)$ and $2.4 \%$ in patients with higher-grade (WHO grade II and III) meningioma $(p=0.14)$.

\section{Asymptomatic vs symptomatic patients}

Comparison of baseline characteristics and outcomes between symptomatic and asymptomatic patients are provided in Tables 2 and 3. A total of 327 asymptomatic patients (14.1\%) underwent surgery for meningioma. The asymptomatic patients ranged from $12.6 \%$ in 2014 to $18.2 \%$ in 2011 , and there was no time trend with increasing numbers of surgery on 


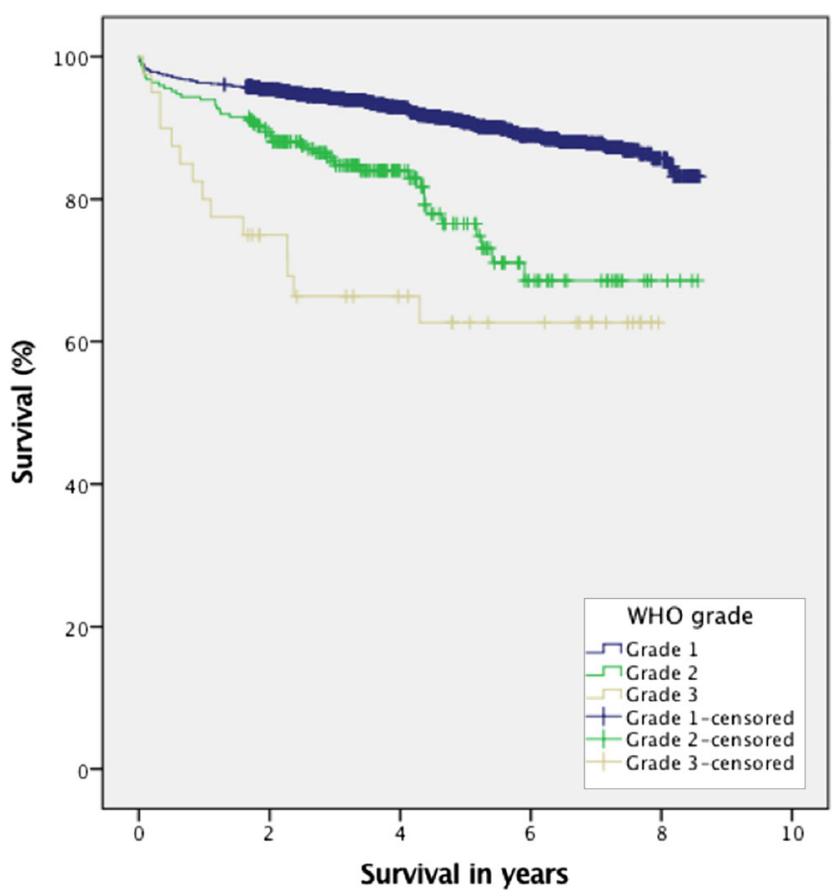

Fig. 1 Survival in meningioma patients depending on WHO grade $(p<0.001)$ asymptomatic patients in the observation period $(p=0.49)$. As shown in Table 2 , the asymptomatic patients were younger and presented with smaller tumors than the symptomatic group (both $p<0.001$ ). Simpson grade 1 and 2 was achieved in $36.7 \%$, respectively, $45.1 \%$ in asymptomatic patients. Postoperative mortality within 30 days of surgery was $0.3 \%$ in asymptomatic patients compared to $1.7 \%$ in the symptomatic patients $(p=0.06)$, with overall survival significantly better in the asymptomatic patients compared with symptomatic patients $(p<0.01)$ (Fig. 2$)$.

\section{Predictive factors in asymptomatic patients}

Due to the significant proportion of postoperative neurological deficits, we explored predictors for new deficits following surgery in asymptomatic patients. Post hoc, we created a multivariable logistic regression model including age, functional status, extension of surgery, sex, meningioma grade, tumor size, and location (skull base and posterior fossa) to identify possible independent predictors for development of new deficit postoperatively. However, we could not identify any predictors based upon the above-mentioned variables.
Table 3 Intraoperative and postoperative variables

\begin{tabular}{|c|c|c|c|c|}
\hline & $\begin{array}{l}\text { Total } \\
(N=2324)\end{array}$ & $\begin{array}{l}\text { Asymptomatic } \\
(N=327)\end{array}$ & $\begin{array}{l}\text { Symptomatic } \\
(N=1996)\end{array}$ & $p$ value \\
\hline Simpson grade & & & & $<0.001$ \\
\hline Grade I & $584(28.3)$ & $101(36.7)$ & $483(27.0)$ & \\
\hline Grade II & $1029(49.8)$ & $124(45.1)$ & $904(50.5)$ & \\
\hline Grade III & $175(8.5)$ & $24(8.7)$ & $151(8.4)$ & \\
\hline Grade IV & $238(11.5)$ & $17(6.2)$ & $221(12.4)$ & \\
\hline Grade IV & $39(1.9)$ & $9(3.3)$ & $30(1.7)$ & \\
\hline $\begin{array}{l}\text { missing }=259 \\
\text { New deficit, } n(\%)\end{array}$ & $344(14.8)$ & $27(8.3)$ & $317(15.9)$ & $<0.001$ \\
\hline $\begin{array}{l}\text { missing }=4 \\
\text { New seizure, } n(\%)\end{array}$ & $105(4.5)$ & $12(3.7)$ & $93(4.7)$ & 0.43 \\
\hline $\begin{array}{l}\text { missing }=4 \\
\text { Hematoma, } n(\%)\end{array}$ & $218(9.4)$ & $15(4.6)$ & $203(10.2)$ & 0.001 \\
\hline $\begin{array}{l}\text { missing }=3 \\
\text { Reoperation due to complication, } \\
\quad n(\%)\end{array}$ & $120(5.2)$ & $7(2.1)$ & $113(5.7)$ & $<0.01$ \\
\hline $\begin{array}{l}\text { missing }=3 \\
\text { Infection, } n(\%)\end{array}$ & $148(6.4)$ & $18(5.5)$ & $130(6.5)$ & 0.49 \\
\hline $\begin{array}{l}\operatorname{missing}=4 \\
\mathrm{VTE}, n(\%)\end{array}$ & $69(3.0)$ & $2(0.6)$ & $67(3.4)$ & $<0.01$ \\
\hline $\begin{array}{l}\text { missing }=4 \\
\text { 30-day mortality, } n(\%)\end{array}$ & $34(1.5)$ & $1(0.3)$ & $33(1.7)$ & 0.06 \\
\hline WHO grade $1, n(\%)$ & $2036(87.6)$ & $292(89.3)$ & $1744(87.4)$ & 0.33 \\
\hline $\begin{array}{l}\text { Planned oncological treatment, } \\
\quad n(\%)\end{array}$ & $125(5.5)$ & $18(5.6)$ & $107(5.4)$ & 0.92 \\
\hline missing $=32$ & & & & \\
\hline
\end{tabular}




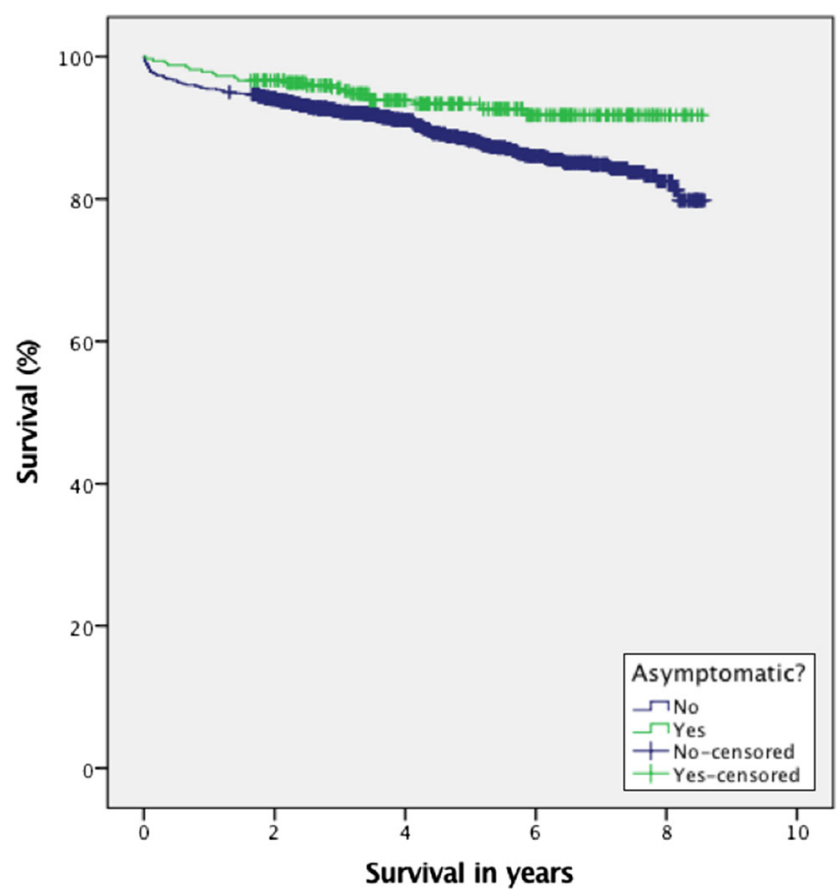

Fig. 2 Survival in asymptomatic compared to symptomatic meningioma patients $(p<0.01)$

\section{Complications in relation to Simpson grade}

We also evaluated if complications were associated with Simpson grading. However, no association between Simpson grade and new onset seizure $(p=0.42)$, VTE $(p=0.42)$, postoperative hematoma $(p=0.29)$, postoperative infection $(p=$ $0.20)$, or reoperation due to complications $(p=0.63)$ was observed. Contrary, there was an association between Simpson grade and new or worsened neurological deficit $(p<0.001)$. New or worsened neurological deficit were observed in $14 \%$ of Simpson grade 1, 12\% of Simpson grade 2, 19\% in Simpson grade 3, 25\% in Simpson grade 4, and 28\% in Simpson grade 5.

\section{Discussion}

In this nationwide registry-based study of patients undergoing surgery for intracranial meningioma, we benchmark the 30day complication rate for clinically relevant complications. The risk of reoperation within 30 days of surgery due to complications was $5.2 \%$, new focal neurological deficit occurred in $14.8 \%$, new-onset seizures in $4.5 \%$, VTE occurred in $3.0 \%$, and the 30 -day mortality was $1.5 \%$. These real-world data on short-term outcomes may be useful in the decision-making process and prior to surgery.

\section{Perioperative outcomes}

We found that the most common postoperative complication to be new onset focal neurological deficit, which is in agreement with previous studies [39]. In the literature, the proportion experiencing new or worsened deficit in unselected patients with meningioma is $8.3-9.3 \%[9,39]$. A retrospective single-center study from 1984 reported postoperative deficits in $10.8 \%$ of patients during the first 30 -day postoperative period, and thus, our data with $14.8 \%$ new deficits appears unfavorable [9]. However, it is difficult to compare with retrospective assessment with standardized prospective registration due to detection bias [12]. In selected materials, the range is wider and much affected by tumor location and preoperative symptomatology [10, 27, 31]. In general, the literature reports improvement of neurological deficits in most patients during the initial follow-up time after surgery [9, 40]. Additionally, the short-term neurological deficit may also predispose for other medical complications in the postoperative period [39].

Onset of seizures after meningioma surgery is a renowned concern, explaining the interest in prophylactic treatment with antiepileptic drugs (AED) [23], although the current evidence indicates no clear benefits in prevention of postoperative seizures with routine perioperative AED administration [20,38]. Routine perioperative administration of AED is not performed at any of the neurosurgical centers in Sweden. In this study, new onset seizures occurred in $4.5 \%$ and this is in line with the existing literature where new onset seizure postoperatively was reported in the range 1.9 to $19.4 \%[23,36,38,43]$. In a recent systematic review and meta-analysis, among the 1085 patients with supratentorial meningiomas without seizures prior to surgery, new-onset seizures occurred in $12.3 \%$ [13]. This large variability between the reported seizure frequency in the literature may be due to different lengths of follow-up, meningioma location, and pattern of evaluation because retrospective cross-sectional studies may capture different aspects than standardized and prospective reporting.

Postoperative hematoma following meningioma surgery was $9.4 \%$ and the percentage undergoing reoperation due to any cause within 30 days was $5.2 \%$. The variable "postoperative hematoma" reported in to the SBTR is defined as symptomatic hematoma without additional information regarding what kind of symptoms. Reviewing the literature, postoperative hematomas in need of surgical evacuation were reported in the range of $2.1-7.1 \%[14,17,22]$. In a prospective study by Geßler et al. using postoperative imaging in 113 patients with meningioma, there were 30 patients $(26.5 \%)$ who experienced symptoms postoperatively, including prolonged awakening, seizures, and neurological deficit [15]. A total of 28 patients $(24.7 \%)$ experienced postoperative symptoms and radiological verified hematoma. Two patients underwent reoperation due to a hematoma, which represents $1.8 \%$ of the cohort of 113 patients. The frequency of postoperative hematoma may seem high in our cohort, but since reoperations due to any cause occurred in $5.2 \%$ of patients, this seems comparable with previous reports. It is not reported to the registry the cause of operation within 30 days, but according to literature, 
the majority of the reoperations within 30 days after surgery of intracranial tumors were due to hematomas, leakage of cerebrospinal fluid, or infection [22, 32, 41].

Venous thromboembolism occurred in $3.0 \%$ of our cohort, in accordance with previous results where numbers ranged from 3.6 to $7.2 \%$ [17, 35]. In SBTR, we are unable to differentiate deep vein thrombosis from pulmonary embolism. The risk-benefit of routine anticoagulation prophylaxis should be carefully weighed given the ratio of hematoma/VTE seen in an unselected meningioma cohort [35]. The timing of complications also indicates that prophylaxis may be safer to delay until $>24 \mathrm{~h}$ postoperatively [41].

The 30-day mortality in Sweden after surgery for intracranial meningioma is currently at $1.5 \%$. This corresponds to similar findings in a Norwegian study where the overall surgical mortality of intracranial tumor surgery within 30 days was reported at $2.3 \%$ and for only meningiomas $0.9 \%$ [22]. As expected, case selection is a strong predictor of outcome because studies on small meningiomas $(<3 \mathrm{~cm})$ and convexity meningiomas show no 30-day mortality [27, 31], and similarly, we present $0.3 \%$ mortality within 30 days in asymptomatic patients while $2.4 \%$ for patients with higher-grade meningiomas. A study from 1984 showed a mortality rate of $4.0 \%$ during the first 30-day postoperative period for intracranial meningiomas [9]; hence, surgical treatment appears safer in modern neurosurgery. This improvement may be due to better surgical and anesthesiologic techniques, but treatment at an earlier time-point with less burden of disease due to better access to imaging may also contribute [37].

\section{Asymptomatic patients}

Due to the usually indolent natural course, some argue that surgery should be reserved for larger meningiomas, meningiomas that exhibit growth, or meningiomas that become symptomatic $[8,16]$. Nevertheless, in clinical practice, the treatment plan is often individualized and adjusted for each patient, including patient's preference. In principle, the treatment should be better than the natural history and, in this regard, a short-term neurological morbidity of $8.3 \%$ must be considered. Unfortunately, surgical indications are not reported in this study (e.g., radiological growth, patients wish), and hence, we cannot make direct assumptions of the expected natural course. In the literature, new neurological deficits in the shortterm following surgery of asymptomatic patients are reported in a wide range with respect to frequency and severity $[21,29$, 44]. Thus, identifying patients with higher risk is of importance and both tumor size and location are presumably important, but also factors such as longer lasting surgery, poor functional status, and high patient age may impact postoperative outcome [5]. We also explored possible predictive factors for neurological deficits after surgery but we were unable to identify any maybe due to rather crude variables.

\section{Registry-based meningioma studies}

Studies relying on data from clinical registries and administrative databases are useful for evaluating treatment strategies and add a different dimension to the results of more selective randomized controlled trials. This kind of research is especially valuable in the field of neurosurgery, where large variations in clinical practice exist $[3,19]$. Moreover, clinical registries and administrative databases allow inclusion of large patient groups that are ineligible for inclusion in randomized trials due to age and comorbidity. Additionally, registry-based studies allow monitoring of trends, costs, and complications of surgical procedures in a real-world setting.

Still, registry-based studies must build upon what is reported to a registry, sometimes limiting chances to explore potential interesting associations. However, for variables included, it is possible to collect large amounts of data in a population-based setting. The SBTR collects data from all regions in Sweden and has a good coverage and established systems for quality control, which makes it a useful source of information concerning collected quality metrics. The baseline characteristics captured by SBTR is similar to previous large-scale and populationbased reports $[1,39]$. Very few studies have been published with registry-based data regarding meningioma using data from the Surveillance, Epidemiology and End Results (SEER) registry $[1,2]$. In comparison, the SBTR data contain important information on symptoms and the functional level as shown in Table 1. In addition, the SEER national tumor database collects reports from 20 regional cancer registries, which includes approximately $28 \%$ of the population in USA, making this registry not entirely representative of the national meningioma population. Another large registry used for patients with meningioma is the National Cancer Data Base (NCDB) [26]. Two large studies have been performed with data from this registry where the main aim of the studies have been gross total resection and predictors of improved survival as well as factors for survival in meningiomas [25, 34]. These studies do, however, lack the postoperative short-term aspects with regard to complications and surgically acquired deficits, aspects that may be important in the decision-making process.

\section{Strengths and limitations}

Limitations of this study include those inherent to registrybased studies with limited details and without possibility to complete missing data. Specifically, there is a lack of detail for variables including radiological parameters, meningioma location, and radiosurgery. The lack of long-term data if neurological deficits were transient or permanent is another limitation. Also, surgeon-evaluated deficit may not be sensitive for all aspects compared to patient-reported deficit [12]. Finally, some variables may be subject to considerable interpretation (e.g., postoperative hematoma) while others are more robust (e.g., 
VTE, reoperation due to complication). Strengths include a truly population-based inclusion of a large number of meningioma patients from a recent time period where data are reported prospectively in a continuous and standardized fashion. Due to the regionalized health care system, any major complication in the post-operative course is treated at the same department that performed the primary surgery. Consequently, we expect that most major complications are reported to the SBTR.

\section{Conclusion}

We have in this registry-based study on meningioma benchmarked the 30-day complication rate and, in addition, presented current neurosurgical outcome in relation to preoperative symptoms and WHO grade. Since surgical decisionmaking is a careful consideration of short-term risk versus long-term benefit, this information may be useful for both caregivers and patients.

Acknowledgements This project was made possible by the continuous work of the Swedish Brain Tumor Registry (SBTR), Roger Henriksson (chairman), Thomas Asklund, Annika Malmström, Lena Damer, Lena Rosenlund, Rickard Sjöberg, Sofia Hylin, Peter Milos, Thomas Blystad, Sara Kinhult, Göran Hesselager, Petra Witt Nyström, Katja Werlenius, Asgeir S. Jakola, Gregor Tomasevic, Magnus Olivecrona, Margret Jensdottir, Michael Bergqvist, Marie Sjögren, Eskil Degsell, Linnea Nilsson, Kerstin Rehn, Kristina Lundqvist, and Lisa Tykosson.

We thank Per-Anders Jansson at Gothia Forum for help with revision of grammar and style.

Funding This study received financial support in the form of ALF-grant (ALFGBG-716671) and funding from the Swedish Research Council (2017-00944). The sponsors had no role in the design or conduct of this research.

\section{Compliance with ethical standards}

Conflict of interest All authors certify that they have no affiliations with or involvement in any organization or entity with any financial interest (such as honoraria; educational grants; participation in speakers' bureaus; membership, employment, consultancies, stock ownership, or other equity interest; and expert testimony or patent-licensing arrangements), or non-financial interest (such as personal or professional relationships, affiliations, knowledge, or beliefs) in the subject matter or materials discussed in this manuscript.

Ethical approval This project was approved by the regional ethical committee in Western Sweden (DNR 363-17) and by the registry holder. This article does not contain any studies with human participants performed by any of the authors.

Open Access This article is distributed under the terms of the Creative Commons Attribution 4.0 International License (http:// creativecommons.org/licenses/by/4.0/), which permits unrestricted use, distribution, and reproduction in any medium, provided you give appropriate credit to the original author(s) and the source, provide a link to the Creative Commons license, and indicate if changes were made.
Publisher's note Springer Nature remains neutral with regard to jurisdictional claims in published maps and institutional affiliations.

\section{References}

1. Agarwal V, McCutcheon BA, Hughes JD, Carlson ML, Glasgow AE, Habermann EB, Nguyen QB, Link MJ, Van Gompel JJ (2017) Trends in Management of Intracranial Meningiomas: analysis of 49,921 cases from modern cohort. World Neurosurg 106:145151. https://doi.org/10.1016/j.wneu.2017.06.127

2. Aizer AA, Bi WL, Kandola MS, Lee EQ, Nayak L, Rinne ML, Norden AD, Beroukhim R, Reardon DA, Wen PY, Al-Mefty O, Arvold ND, Dunn IF, Alexander BM (2015) Extent of resection and overall survival for patients with atypical and malignant meningioma. Cancer 121:4376-4381. https://doi.org/10.1002/cncr. 29639

3. Al-Shahi Salman R, White PM, Counsell CE, du Plessis J, van Beijnum J, Josephson CB, Wilkinson T, Wedderburn CJ, Chandy Z, St George EJ, Sellar RJ, Warlow CP (2014) Outcome after conservative management or intervention for unruptured brain arteriovenous malformations. Jama 311:1661-1669. https://doi.org/10. 1001/jama.2014.3200

4. Asklund T, Malmstrom A, Bergqvist M, Bjor O, Henriksson R (2015) Brain tumors in Sweden: data from a population-based registry 1999-2012. Acta Oncol 54:377-384. https://doi.org/10.3109/ 0284186x.2014.975369

5. Bartek J Jr, Sjavik K, Forander P, Solheim O, Gulati S, Weber C, Ingebrigtsen T, Jakola AS (2015) Predictors of severe complications in intracranial meningioma surgery: a population-based multicenter study. World Neurosurg 83:673-678. https://doi.org/10. 1016/j.wneu.2015.01.022

6. Bhat AR, Wani MA, Kirmani AR, Ramzan AU (2014) Histological-subtypes and anatomical location correlated in meningeal brain tumors (meningiomas). J Neurosci Rural Pract 5:244249. https://doi.org/10.4103/0976-3147.133568

7. Black PM (1993) Meningiomas. Neurosurgery 32:643-657

8. Chamoun R, Krisht KM, Couldwell WT (2011) Incidental meningiomas. Neurosurg Focus 31:E19. https://doi.org/10.3171/2011.9. focus 11220

9. Chan RC, Thompson GB (1984) Morbidity, mortality, and quality of life following surgery for intracranial meningiomas. A retrospective study in 257 cases. J Neurosurg 60:52-60. https://doi.org/10. 3171/jns.1984.60.1.0052

10. Chen ZY, Zheng CH, Tang L, Su XY, Lu GH, Zhang CY, Xiao SW, Tan YF (2015) Intracranial meningioma surgery in the elderly (over 65 years): prognostic factors and outcome. Acta Neurochir 157: 1549-1557; discussion 1557. https://doi.org/10.1007/s00701-0152502-9

11. De Witt Hamer PC, Robles SG, Zwinderman AH, Duffau H, Berger MS (2012) Impact of intraoperative stimulation brain mapping on glioma surgery outcome: a meta-analysis. J Clin Oncol 30:25592565. https://doi.org/10.1200/jco.2011.38.4818

12. Drewes C, Sagberg LM, Jakola AS, Gulati S, Solheim O (2015) Morbidity after intracranial tumor surgery: sensitivity and specificity of retrospective review of medical records compared with patient-reported outcomes at 30 days. J Neurosurg 123:972-977. https://doi.org/10.3171/2014.12.Jns142206

13. Englot DJ, Magill ST, Han SJ, Chang EF, Berger MS, McDermott MW (2016) Seizures in supratentorial meningioma: a systematic review and meta-analysis. J Neurosurg 124:1552-1561. https:// doi.org/10.3171/2015.4.Jns 142742

14. Gerlach R, Raabe A, Scharrer I, Meixensberger J, Seifert V (2004) Post-operative hematoma after surgery for intracranial meningiomas: causes, avoidable risk factors and clinical outcome. Neurol Res 26:61-66. https://doi.org/10.1179/016164104773026543 
15. Geßler F, Dützmann S, Quick J, Tizi K, Voigt MA, Mutlak H, Vatter H, Seifert V, Senft C (2015) Is postoperative imaging mandatory after meningioma removal? Results of a prospective study. PLoS One 10. https://doi.org/10.1371/journal.pone.0124534

16. Goldbrunner R, Minniti G, Preusser M, Jenkinson MD, Sallabanda K, Houdart E, von Deimling A, Stavrinou P, Lefranc F, LundJohansen M, Moyal EC, Brandsma D, Henriksson R, Soffietti R, Weller M (2016) EANO guidelines for the diagnosis and treatment of meningiomas. The Lancet Oncology 17:e383-e391. https://doi. org/10.1016/s1470-2045(16)30321-7

17. Hoefnagel D, Kwee LE, van Putten EH, Kros JM, Dirven CM, Dammers R (2014) The incidence of postoperative thromboembolic complications following surgical resection of intracranial meningioma. A retrospective study of a large single center patient cohort. Clin Neurol Neurosurg 123:150-154. https://doi.org/10.1016/j. clineuro.2014.06.001

18. Jadid KD, Feychting M, Hoijer J, Hylin S, Kihlstrom L, Mathiesen $\mathrm{T}$ (2015) Long-term follow-up of incidentally discovered meningiomas. Acta Neurochir 157:225-230; discussion 230. https://doi. org/10.1007/s00701-014-2306-3

19. Jakola AS, Myrmel KS, Kloster R, Torp SH, Lindal S, Unsgard G, Solheim O (2012) Comparison of a strategy favoring early surgical resection vs a strategy favoring watchful waiting in low-grade gliomas. Jama 308:1881-1888. https://doi.org/10.1001/jama.2012.12807

20. Komotar RJ, Raper DM, Starke RM, Iorgulescu JB, Gutin PH (2011) Prophylactic antiepileptic drug therapy in patients undergoing supratentorial meningioma resection: a systematic analysis of efficacy. J Neurosurg 115:483-490. https://doi.org/10.3171/2011.4. Jns101585

21. Kuratsu J, Kochi M, Ushio Y (2000) Incidence and clinical features of asymptomatic meningiomas. J Neurosurg 92:766-770. https:// doi.org/10.3171/jns.2000.92.5.0766

22. Lassen B, Helseth E, Ronning P, Scheie D, Johannesen TB, Maehlen J, Langmoen IA, Meling TR (2011) Surgical mortality at 30 days and complications leading to recraniotomy in 2630 consecutive craniotomies for intracranial tumors. Neurosurgery 68: 1259-1268; discussion 1268-1259. https://doi.org/10.1227/NEU. 0b013e31820c0441

23. Lieu AS, Howng SL (2000) Intracranial meningiomas and epilepsy: incidence, prognosis and influencing factors. Epilepsy Res 38:45-52

24. Louis DN, Perry A, Reifenberger G, von Deimling A, FigarellaBranger D, Cavenee WK, Ohgaki H, Wiestler OD, Kleihues P, Ellison DW (2016) The 2016 World Health Organization classification of tumors of the central nervous system: a summary. Acta Neuropathol 131:803-820. https://doi.org/10.1007/s00401-016$1545-1$

25. McCarthy BJ, Davis FG, Freels S, Surawicz TS, Damek DM, Grutsch J, Menck HR, Laws ER Jr (1998) Factors associated with survival in patients with meningioma. J Neurosurg 88:831-839. https://doi.org/10.3171/jns.1998.88.5.0831

26. Mohanty S, Bilimoria KY (2014) Comparing national cancer registries: the National Cancer Data Base (NCDB) and the surveillance, epidemiology, and end results (SEER) program. J Surg Oncol 109:629-630. https://doi.org/10.1002/jso.23568

27. Morokoff AP, Zauberman J, Black PM (2008) Surgery for convexity meningiomas. Neurosurgery 63:427-433; discussion 433-424. https://doi.org/10.1227/01.Neu.0000310692.80289.28

28. Nakamura M, Roser F, Michel J, Jacobs C, Samii M (2003) The natural history of incidental meningiomas. Neurosurgery 53:62-70 discussion 70-61

29. Nishizaki T, Ozaki S, Kwak T, Ito H (1999) Clinical features and surgical outcome in patients with asymptomatic meningiomas. Br J Neurosurg 13:52-55

30. Ostrom QT, Gittleman H, Liao P, Vecchione-Koval T, Wolinsky Y, Kruchko C, Barnholtz-Sloan JS (2017) CBTRUS statistical report: primary brain and other central nervous system tumors diagnosed in the United States in 2010-2014. Neuro-Oncology 19:v1-v88. https://doi.org/10.1093/neuonc/nox158

31. Reinert M, Babey M, Curschmann J, Vajtai I, Seiler RW, Mariani L (2006) Morbidity in 201 patients with small sized meningioma treated by microsurgery. Acta Neurochir 148:1257-1265; discussion 1266. https://doi.org/10.1007/s00701-006-0909-z

32. Roberti F, Sekhar LN, Kalavakonda C, Wright DC (2001) Posterior fossa meningiomas: surgical experience in 161 cases. Surg Neurol 56:8-20 discussion 20-21

33. Rockhill J, Mrugala M, Chamberlain MC (2007) Intracranial meningiomas: an overview of diagnosis and treatment. Neurosurg Focus 23:E1. https://doi.org/10.3171/foc-07/10/e1

34. Rydzewski NR, Lesniak MS, Chandler JP, Kalapurakal JA, Pollom E, Tate MC, Bloch O, Kruser T, Dalal P, Sachdev S (2018) Gross total resection and adjuvant radiotherapy most significant predictors of improved survival in patients with atypical meningioma. Cancer 124:734-742. https://doi.org/10.1002/cncr.31088

35. Sjavik K, Bartek J Jr, Solheim O, Ingebrigtsen T, Gulati S, Sagberg LM, Forander P, Jakola AS (2016) Venous thromboembolism prophylaxis in meningioma surgery: a population-based comparative effectiveness study of routine mechanical prophylaxis with or without preoperative low-molecular-weight heparin. World Neurosurg 88:320-326. https://doi.org/10.1016/j.wneu.2015.12.077

36. Skardelly M, Rother C, Noell S, Behling F, Wuttke TV, Schittenhelm J, Bisdas S, Meisner C, Rona S, Tabatabai G, Roser F, Tatagiba MS (2017) Risk factors of preoperative and early postoperative seizures in patients with meningioma: a retrospective single-center cohort study. World Neurosurg 97:538-546. https:// doi.org/10.1016/j.wneu.2016.10.062

37. Solheim O, Torsteinsen M, Johannesen TB, Jakola AS (2014) Effects of cerebral magnetic resonance imaging in outpatients on observed incidence of intracranial tumors and patient survival: a national observational study. J Neurosurg 120:827-832. https:// doi.org/10.3171/2013.12.jns131312

38. Sughrue ME, Rutkowski MJ, Chang EF, Shangari G, Kane AJ, McDermott MW, Berger MS, Parsa AT (2011) Postoperative seizures following the resection of convexity meningiomas: are prophylactic anticonvulsants indicated? Clinical article. J Neurosurg 114:705-709. https://doi.org/10.3171/2010.5.Jns091972

39. Sughrue ME, Rutkowski MJ, Shangari G, Chang HQ, Parsa AT, Berger MS, McDermott MW (2011) Risk factors for the development of serious medical complications after resection of meningiomas. Clinical article. J Neurosurg 114:697-704. https://doi.org/10. 3171/2010.6.jns091974

40. van Alkemade H, de Leau M, Dieleman EM, Kardaun JW, van Os R, Vandertop WP, van Furth WR, Stalpers LJ (2012) Impaired survival and long-term neurological problems in benign meningioma. Neuro-Oncology 14:658-666. https://doi.org/10.1093/neuonc/ nos013

41. Viken HH, Iversen IA, Jakola A, Sagberg LM, Solheim O (2018) When are complications after brain tumor surgery detected? World Neurosurg 112:e702-e710. https://doi.org/10.1016/j.wneu.2018. 01.137

42. Whittle IR, Smith C, Navoo P, Collie D (2004) Meningiomas. Lancet 363:1535-1543. https://doi.org/10.1016/s0140-6736(04) 16153-9

43. Wirsching HG, Morel C, Gmur C, Neidert MC, Baumann CR, Valavanis A, Rushing EJ, Krayenbuhl N, Weller M (2016) Predicting outcome of epilepsy after meningioma resection. Neuro-Oncology 18:1002-1010. https://doi.org/10.1093/neuonc/ nov303

44. Zeng L, Wang L, Ye F, Chen J, Lei T, Chen J (2015) Clinical characteristics of patients with asymptomatic intracranial meningiomas and results of their surgical management. Neurosurg Rev 38: 481-488; discussion 488. https://doi.org/10.1007/s10143-015$0619-1$ 